\title{
Antioxidant and antimicrobial properties of dried Portuguese apple variety (Malus domestica Borkh. cv Bravo de Esmolfe)
}

\author{
Tânia C.S.P. Pires ${ }^{\mathrm{a}, \mathrm{b}, \mathrm{c}}$, Maria Inês Dias ${ }^{\mathrm{a}}$, Lillian Barros ${ }^{\mathrm{a}}$, Maria José Alves ${ }^{\mathrm{a}, \mathrm{d}}$, \\ M. Beatriz P.P. Oliveira ${ }^{\mathrm{c}}$, Celestino Santos-Buelga ${ }^{\mathrm{b}}$, Isabel C.F.R. Ferreira ${ }^{\mathrm{a}, *}$ \\ a Centro de Investigação de Montanha (CIMO), Instituto Politécnico de Bragança, Campus de Santa Apolónia, 5300-253 Bragança, Portugal \\ b Grupo de Investigación en Polifenoles (GIP-USAL), Facultad de Farmacia, Universidad de Salamanca, Campus Miguel de Unamuno s/n, 37007 Salamanca, Spain \\ ${ }^{c}$ REQUIMTE/LAQV, Science Chemical Department, Faculty of Pharmacy of University of Porto, Rua Jorge Viterbo Ferreira, 228, 4050-313 Porto, Portugal \\ d School of Health, Polytechnic Institute of Bragança, Av. D. Afonso V, 5300-121 Bragança, Portugal
}

\section{A R T I C L E I N F O}

\section{Keywords:}

Malus domestica Borkh

Nutritional value

Chemical composition

Bioactive properties

\begin{abstract}
A B S T R A C T
Malus domestica Borkh apples are one of the most consumed fruits in the world, due to their sweetness and flavour. Herein, 'Bravo de Esmolfe' apple fruits were characterized regarding their nutritional value, chemical composition and bioactive properties. Besides nutrients, flavan-3-ols (i.e., epicatechin and B-type procyanidins) as also hydroxycinnamoyl-quinic acids and phloretin derivatives were identified in the samples. Extracts prepared from 'Bravo de Esmolfe' also proved to have antioxidant activity and antibacterial effects against Grampositive bacteria, namely methicillin-susceptible Staphylococcus aureus (MSSA), methicillin-resistant Staphylococcus aureus (MRSA), Listeria monocytogenes and Enterococcus faecalis, and against the Gram-negative bacteria Escherichia coli, Escherichia coli (ESBL) (producing extended spectrum $\beta$-lactamases) and Morganella morganii. There is very little information about 'Bravo de Esmolfe' apple, so this study is important to inform consumers about an alternative source of nutritional and bioactive compounds.
\end{abstract}

\section{Introduction}

'Bravo de Esmolfe' is a Portuguese apple variety with an intense aroma, highly appreciated by consumers. This apple was recognised as a product with Protected Designation of Origin (PDO), being therefore a high added value product with impact in the local and national economy $\left(\mathrm{N}^{0} 1107 / 96\right.$, 2001; Reis, Rocha, Barros, Delgadillo, \& Coimbra, 2009). In the last few years the 'Bravo de Esmolfe' apple has doubled its price compared to exotic varieties, such as Golden and Starking (Feliciano et al., 2010). Its production is carried out in a restricted and small inland region in northern Portugal, corresponding to a production of $200,000 \mathrm{~kg}$ per year, but commercial demand is now increasing, due to its appealing sensory properties, namely sweetness and flavour (Bhatti \& Jha, 2010). The regular consumption of fruits and vegetables has been associated with reduced risk of developing chronic diseases. These benefits are often attributed to their high phytochemical content and antioxidant power (Serra et al., 2010). Apple fruits have a wide variety and well-balanced composition, being moderately energetic and well-proportioned in sugar and acid contents, giving it a pleasant taste. The chemical composition of apples varies depending on the cultivar, production region and horticultural practices (Róth et al., 2007).
They are mostly constituted by water (84\%), minerals, complex B vitamins (Feliciano et al., 2010), monosaccharides, dietary fibre, and various biologically active compounds, such as vitamin C, and certain phenolic compounds (Róth et al., 2007; Wu et al., 2007) Feliciano et al., (Feliciano et al., 2010) studied several nutritional parameters in apple varieties, including the "Bravo de Esmolfe" apple. Wu et al. (Wu et al., 2007) reported the sugars and organic acids composition as also the phenolic profile of different apple cultivars. Various authors (Malec et al., 2014; Mayr, Treutter, SantosBuelga, Bauer, \& Feucht, 1995; Scafuri et al., 2016; Shoji, Masumoto, Moriichi, Kanda, \& Ohtake, 2006; Shoji et al., 2003; Verdu et al., 2013; Wojdyło, Oszmiański, \& Laskowski, 2008) also presented the phenolic profile of different apple cultivars, but none of the previously mentioned authors have studied the bioactive properties and compounds from the cultivar 'Bravo de Esmolfe'. Therefore, to the best of the author's knowledge, there is still scarce information about this apple variety.

The aim of the present work, was to characterize the nutritional and chemical composition of Malus domestica Borkh cv 'Bravo de Esmolfe', as also its bioactive properties in terms of phenolic compounds, antioxidant and antibacterial properties.

\footnotetext{
* Corresponding author.

E-mail address: iferreira@ipb.pt (I.C.F.R. Ferreira).
} 


\section{Materials and methods}

\subsection{Standards and reagents}

HPLC grade acetonitrile (99.9\%), $n$-hexane (95\%) and ethyl acetate (99.8\%) were purchased from Fisher Scientific (Lisbon, Portugal). Fatty acids methyl ester (standard 47885-U), formic acid, 6-hydroxy-2,5,7,8-tetramethylchroman-2-carboxylic acid (Trolox), L-ascorbic acid, tocopherol, sugars and organic acid standards were obtained from Sigma-Aldrich (St. Louis, MO, USA). Phenolic standards were acquired from Extrasynthèse (Genay, France). 2,2-Diphenyl-1-picrylhydrazyl (DPPH) was obtained from Alfa Aesar (Ward Hill, MA, USA). p-Iodonitrotetrazolium chloride (INT) from Panreac Applichem (Barcelona, Spain), Tryptic Soy Broth (TSB) and Mueller-Hinton (MH) from Biolab ${ }^{\circledR}$ (Hungary). All other general laboratory reagents were purchased from Panreac Química S.L.U. (Barcelona, Spain). Water was treated in a Milli-Q water purification system (TGI Pure Water Systems, USA).

\subsection{Samples}

Apple samples (Malus domestica Borkh. cv 'Bravo de Esmolfe'), were kindly supplied by the RBR foods company from Castro Daire (Portugal), in the dry form (without skin), since the company's objective is to market this as a snack. After reception, the material was reduced to a fine dried powder ( 20 mesh), mixed to obtain a homogenate sample and stored in a desiccator, protected from light, until further analysis. All the assays were performed in triplicate.

\subsection{Nutritional composition}

The proximate composition was determined according to AOAC procedures (AOAC, 2016), including protein by the macro-Kjeldahl method (991.02); crude fat using a Soxhlet apparatus and extracting the powdered sample with petroleum ether (989.05) and ash contents (935.42) by incineration at $550 \pm 15^{\circ} \mathrm{C}$. The total carbohydrates (including fiber) were calculated by difference ([Total carbohydrates $(\mathrm{g} / 100 \mathrm{~g})=100-(\mathrm{g}$ fat $+\mathrm{g}$ protein $+\mathrm{g}$ ash $)])$ and total energy was calculated according to the following equation: Energy (kcal/100 g) $=4 \times(\mathrm{g}$ proteins $+\mathrm{g}$ carbohydrates $)+9 \times(\mathrm{g}$ fat $)$.

\subsection{Fatty acids}

Fatty acids were determined after Soxhlet extraction using the powdered sample and after a trans-esterification process. The analysis was performed by GC-FID (DANI model GC 1000 instrument, Contone, Switzerland) and separation was achieved using a Macherey-Nagel (Düren, Germany) column (50\% cyanopropyl-methyl-50\% phenylmethylpolysiloxane, $30 \mathrm{~m} \times 0.32 \mathrm{~mm}$ i.d. $\times 0.25 \mu \mathrm{m} \mathrm{df})$. The results were expressed in relative percentage of each fatty acid (Barros, Pereira, \& Ferreira, 2013; Dias et al., 2015).

\subsection{Tocopherols}

Tocopherols (four isoforms) were analysed in the powdered sample and analysed by HPLC (Knauer, Smartline system 1000, Berlin, Germany) coupled to a fluorescence detector (FP-2020; Jasco, Easton, MD, USA) and separation was achieved using a Polyamide II (5 $\mu \mathrm{m}$, $250 \times 4.6 \mathrm{~mm}$ ) normal-phase column from YMCWaters (YMC America, Inc., Allentown, PA, USA). Tocol was used as an internal standard and the quantification was based on the fluorescence signal response of each standard, The results were expressed in mg per $100 \mathrm{~g}$ of dry plant weight. (Barros et al., 2013; Dias et al., 2015).

\subsection{Soluble sugars}

Soluble sugars were determined in the powdered sample by HPLC coupled to a refraction index detector (HPLC-RI; Knauer, Smartline system 1000, Berlin, Germany), as previously described by Barros et al. (2013). Separation was achieved using a Eurospher 100-5 NH2 column ( $5 \mu \mathrm{m}, 4.6 \times 250 \mathrm{~mm}$, Knauer) and quantification was performed using internal standard method (IS, melezitose). The results were expressed in $\mathrm{g}$ per $100 \mathrm{~g}$ of plant dry weight.

\subsection{Organic acids}

Organic acids were determined in the powdered samples and analysed by HPLC coupled to photodiode array detector (UFLC-PDA; Shimadzu Corporation, Kyoto, Japan) and separation was performed with a SphereClone (Phenomenex, Torrance, CA, USA) reverse phase C18 column $(5 \mu \mathrm{m}, 250 \times 4.6 \mathrm{~mm}$ i.d.). The quantification was performed by comparison of the peak area recorded at $215 \mathrm{~nm}$ as preferred wavelength. The results were expressed in $\mathrm{g}$ per $100 \mathrm{~g}$ of plant dry weight (Barros et al., 2013; Dias et al., 2015).

\subsection{Hydromethanolic extracts preparation}

The hydromethanolic extracts were prepared by mixing $1 \mathrm{~g}$ of the powered dried apple sample with a methanol: water mixture (80:20, $v /$ $v)$ at $25^{\circ} \mathrm{C}$ and $30 \mathrm{~g}$ during $1 \mathrm{~h}$, followed by filtration through a Whatman filter paper No. 4 . The remain residue was re-extracted with an additional portion of methanol:water mixture and the combined extracts were evaporated under reduced pressure (rotary evaporator Büchi R-210, Flawil, Switzerland) and stored at $-20^{\circ} \mathrm{C}$ for further analysis.

\subsection{Phenolic compounds analysis}

The phenolic compounds were determined in the hydromethanolic extract solution $(5 \mathrm{mg} / \mathrm{ml})$ by LC-DAD-ESI/MSn (Dionex Ultimate 3000 UPLC, Thermo Scientific, San Jose, CA, USA), following a procedure previously described by the authors (Bessada, Barreira, Barros, Ferreira, \& Oliveira, 2016). Chromatographic separation was performed using a Waters Spherisorb S3 ODS-2 C18 $(3 \mu \mathrm{m}, 4.6 \times 150 \mathrm{~mm})$. For the double online detection, a DAD $(280,330$ and $370 \mathrm{~nm}$ as preferred wavelengths) and a mass spectrometer performed in negative mode (Linear Ion Trap LTQ XL mass spectrometer equipped with an ESI source, ThermoFinnigan, San Jose, CA, USA) were used and connected to the HPLC system. The identification was performed using standard compounds, when available, by comparing their retention times, UV-vis and mass spectra. If no standard compound was available, phenolic compounds were identified by comparing the obtained information with available data reported in the literature, giving a tentative identification. Quantification was made from the areas of the peaks recorded at $280 \mathrm{~nm}$ by comparison with calibration curves obtained from standards. The results were expressed as $\mathrm{mg} / 100 \mathrm{~g}$ dry weight (dw).

\subsection{Antioxidant and antibacterial activity of the hydromethanolic extracts}

The antioxidant activity was evaluated in the extracts re-dissolved in methanol:water mixture (10 to $0.3125 \mathrm{mg} / \mathrm{ml}$ ) through DPPH radical-scavenging, reducing power, inhibition of $\beta$-carotene bleaching and TBARS inhibition assays. Trolox was used as positive control and the results were expressed in $\mathrm{EC}_{50}$ values Barros et al. (2013). The antibacterial activity was determined in the extracts re-dissolved in water (stock solution $20 \mathrm{mg} / \mathrm{ml}$ ). The microorganisms used were clinical isolates from patients hospitalized in various departments of the Local Health Unit of Bragança and Hospital Center of Trás-os-Montes and Alto-Douro Vila Real, Northeast of Portugal. The antibiotic susceptibility profile was screened previously (Dias et al., 2016) for all the tested bacteria. Microdilution method and the rapid $p$-iodonitrotetrazolium chloride (INT) colorimetric assay were used to determine 
Table 1

Nutritional and chemical composition of 'Bravo de Esmolfe' apples (mean \pm SD).

\begin{tabular}{|c|c|c|c|}
\hline \multicolumn{2}{|l|}{ Nutritional value $(\mathrm{g} / 100 \mathrm{~g} d w)$} & \multicolumn{2}{|c|}{ Soluble sugars $(g / 100 \mathrm{~g} \mathrm{dw})$} \\
\hline Fat & $5.9 \pm 0.3$ & Fructose & $19.0 \pm 0.2$ \\
\hline Proteins & $2.61 \pm 0.02$ & Glucose & $8.4 \pm 0.3$ \\
\hline Ash & $1.84 \pm 0.04$ & Sucrose & $1.38 \pm 0.02$ \\
\hline Total carbohydrates & $89.68 \pm 0.03$ & Sum & $28.8 \pm 0.1$ \\
\hline Energy (kcal/100 g dw) & $492 \pm 1$ & & \\
\hline \multicolumn{2}{|c|}{ Fatty acids (relative percentage, \%) } & \multicolumn{2}{|c|}{ Organic acids $(g / 100 g d w)$} \\
\hline C10:0 & $0.63 \pm 0.01$ & Oxalic acid & $0.101 \pm 0.004$ \\
\hline C12:0 & $0.81 \pm 0.01$ & Quinic acid & $0.15 \pm 0.01$ \\
\hline $\mathrm{C} 14: 0$ & $1.92 \pm 0.07$ & Malic acid & $1.36 \pm 0.01$ \\
\hline C14:1 & $2.30 \pm 0.05$ & Shikimic acid & $0.0002 \pm 0.0001$ \\
\hline C15:0 & $1.04 \pm 0.08$ & Sum & $1.6 \pm 0.1$ \\
\hline $\mathrm{C} 16: 0$ & $28.94 \pm 0.07$ & & \\
\hline $\mathrm{C} 17: 0$ & $1.8 \pm 0.1$ & & \\
\hline C18:0 & $16.4 \pm 0.1$ & & \\
\hline C18:1n9 & $5.89 \pm 0.04$ & & \\
\hline C18:2n6 & $15.8 \pm 0.4$ & & \\
\hline $\mathrm{C} 18: 3 \mathrm{n} 3$ & $7.6 \pm 0.3$ & & \\
\hline C20:0 & $1.52 \pm 0.09$ & & \\
\hline C20:3n3 & $0.98 \pm 0.04$ & & \\
\hline $\mathrm{C} 22: 0$ & $3.76 \pm 0.01$ & & \\
\hline C23:0 & $1.02 \pm 0.05$ & & \\
\hline $\mathrm{C} 24: 0$ & $9.6 \pm 0.1$ & & \\
\hline SFA & $67.4 \pm 0.2$ & & \\
\hline MUFA & $8.19 \pm 0.08$ & & \\
\hline PUFA & $24.4 \pm 0.1$ & & \\
\hline Tocopherols $(\mathrm{mg} / 100 \mathrm{~g} \mathrm{dw})$ & & & \\
\hline$\alpha$-Tocopherol & $0.52 \pm 0.02$ & & \\
\hline
\end{tabular}

dw- dry weight basis. C10:0- Capric acid; C12:0- Lauric acid; C14:0- Myristic acid; C14:1 Myristoleic acid; C15:0- Pentadecanoic acid; C16:0- Palmitic acid; C17:0 - Heptadecanoic acid; C18:0 - Stearic acid; C18:1n9- Oleic acid; C18:2n6- Linoleic acid; C18:3n3- Linolenic acid; C20:0- Arachidic acid; C20:3n3 - Eicosatrienoic acid; C22:0 - Behenic acid; C23:0 Tricosanoic acid; C24:0 - Lignoceric acid. SFA- saturated fatty acids, MUFA- monounsaturated fatty acids, PUFA- polyunsaturated fatty acids dw- dry weight basis; Calibration curves for organic acids: oxalic acid $\left(y=9 \times 106 x+45973, R^{2}=0.9901\right)$; quinic acid $\left(y=610607 x+46061, R^{2}=0.9995\right) ;$ malic acid $(y=912441 x+92665$, $\left.R^{2}=0.999\right)$ and shikimic acid $\left(y=7 \times 107 x+175156, R^{2}=0.9999\right) ;(<$ LOD: $12.6,24$, 36 and $0.01 \mu \mathrm{g} / \mathrm{ml}$ for oxalic, quinic, malic and shikimic acids, respectively); (< LOQ: 42, $81,1.2 \times 102$ and $0.02, \mu \mathrm{g} / \mathrm{ml}$ for oxalic, quinic, malic and shikimic acids, respectively). minimum inhibitory concentration (MIC) (Kuete, Ango, et al., 2011; Kuete, Justin, et al., 2011).

\section{Results and discussion}

Data regarding the proximate composition and energetic value of the 'Bravo de Esmolfe' dried apples are shown in Table 1. Carbohydrates were the most abundant macronutrients, followed by fat, proteins and ash. Feliciano et al. (Feliciano et al., 2010) reported lower values of proteins $(0.07 \mathrm{~g} / 100 \mathrm{~g} \mathrm{dw})$. However, USDA (United States Department of Agriculture) reported similar values for carbohydrates (95.72 g/100 g dw) and energetic value (360 kcal/100 g dw) in apple raw samples without skin but lower fat content $(0.97 \mathrm{~g} / 100 \mathrm{~g} \mathrm{dw})$ (USDA, 2016). Sixteen fatty acids were identified with the predominance of saturated fatty acids, mostly palmitic acid, followed by stearic and linoleic acids (28.94\%, 16.4\% and 15.8\%, respectively). Interestingly, previous studies carried out by Wu et al. (Wu et al., 2007) using other apple varieties (Delicious, Golden Delicious, Ralls, Fuji, QinGuan, Granny Smith, Jonagold, Orin and Average), reported linoleic acid as the most abundant fatty acid. $\alpha$-Tocopherol $(0.52 \mathrm{mg} / 100 \mathrm{~g} \mathrm{dw})$ was the only tocopherol isoform found in this sample, which is in agreement with the reported by Feliciano et al., (Feliciano et al., 2010) in 'Bravo de Esmolfe' $(0.75 \mathrm{mg} / 100 \mathrm{~g} \mathrm{dw})$. Fructose, glucose and sucrose were the sugars detected in the analysed sample (19.0, 8.4 and $1.38 \mathrm{~g} / 100 \mathrm{~g} \mathrm{dw}$, respectively), being fructose the most abundant one; these results are also in agreement with previous studies in 'Bravo de Esmolfe' apple (Feliciano et al., 2010). Regarding organic acids, malic acid was the main molecule present, followed by quinic, oxalic and shikimic acids $(1.36,0.15,0.101$ and $0.0002 \mathrm{mg} / 100 \mathrm{~g} \mathrm{dw}$, respectively). These results are in accordance with those reported by Chinnici, Spinabelli, Riponi, \& Amati (Chinnici, Spinabelli, Riponi, \& Amati, 2005), where malic acid was also the main organic acid described in apple juices. Feliciano et al. (Feliciano et al., 2010) and Wu et al. (Wu et al., 2007) reported the presence of other organic acids, such as citric, succinic and fumaric acids in different apple varieties, such as Delicious, Golden Delicious, Ralls, Fuji, QinGuan, Granny Smith, Jonagold, Orin and Average. The differences found in the chemical composition of apples could depend on the cultivar, production region and horticultural practices (Róth et al., 2007).

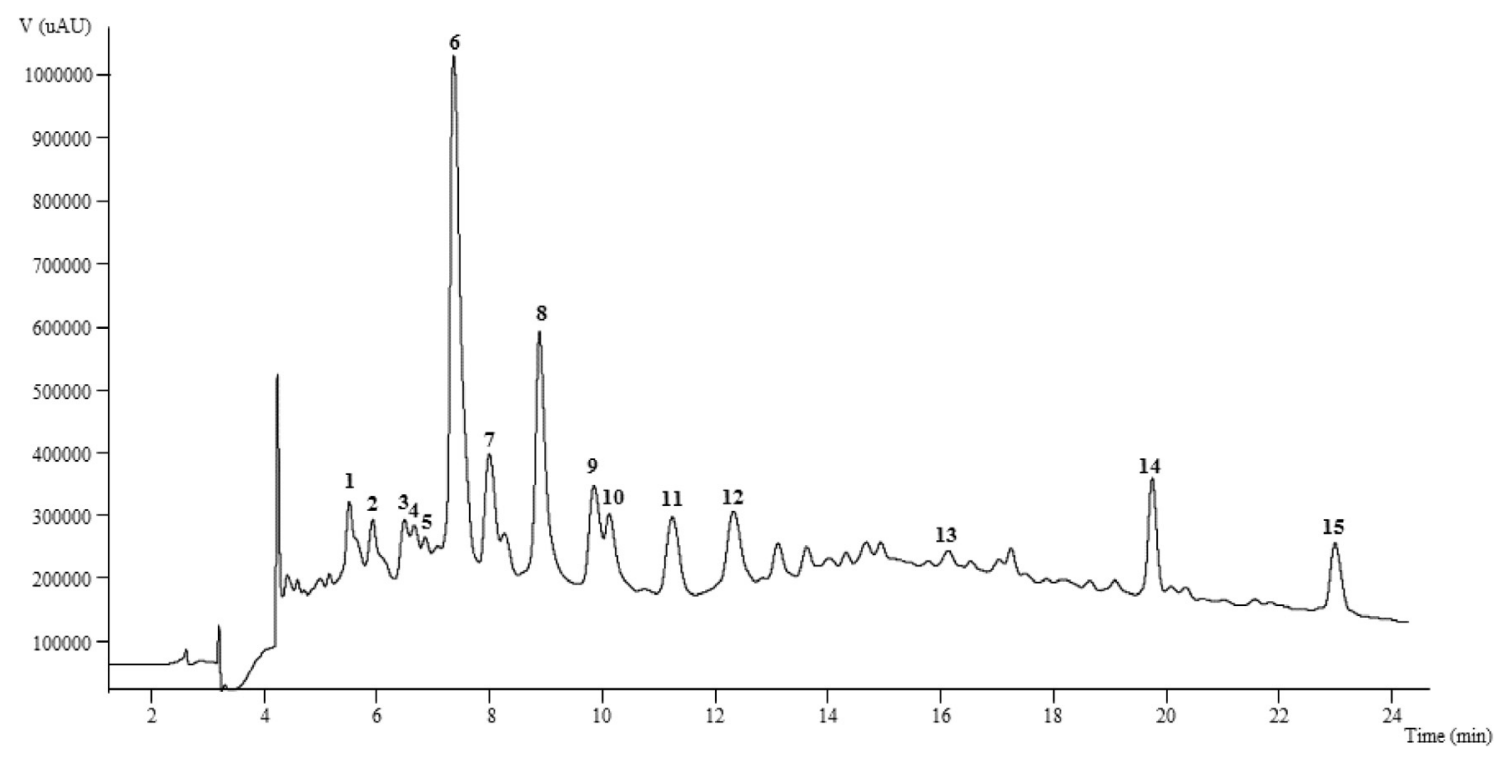

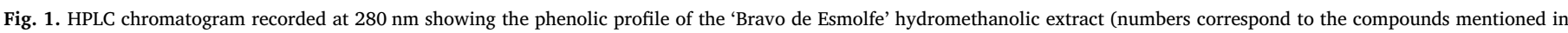
Table 2). 


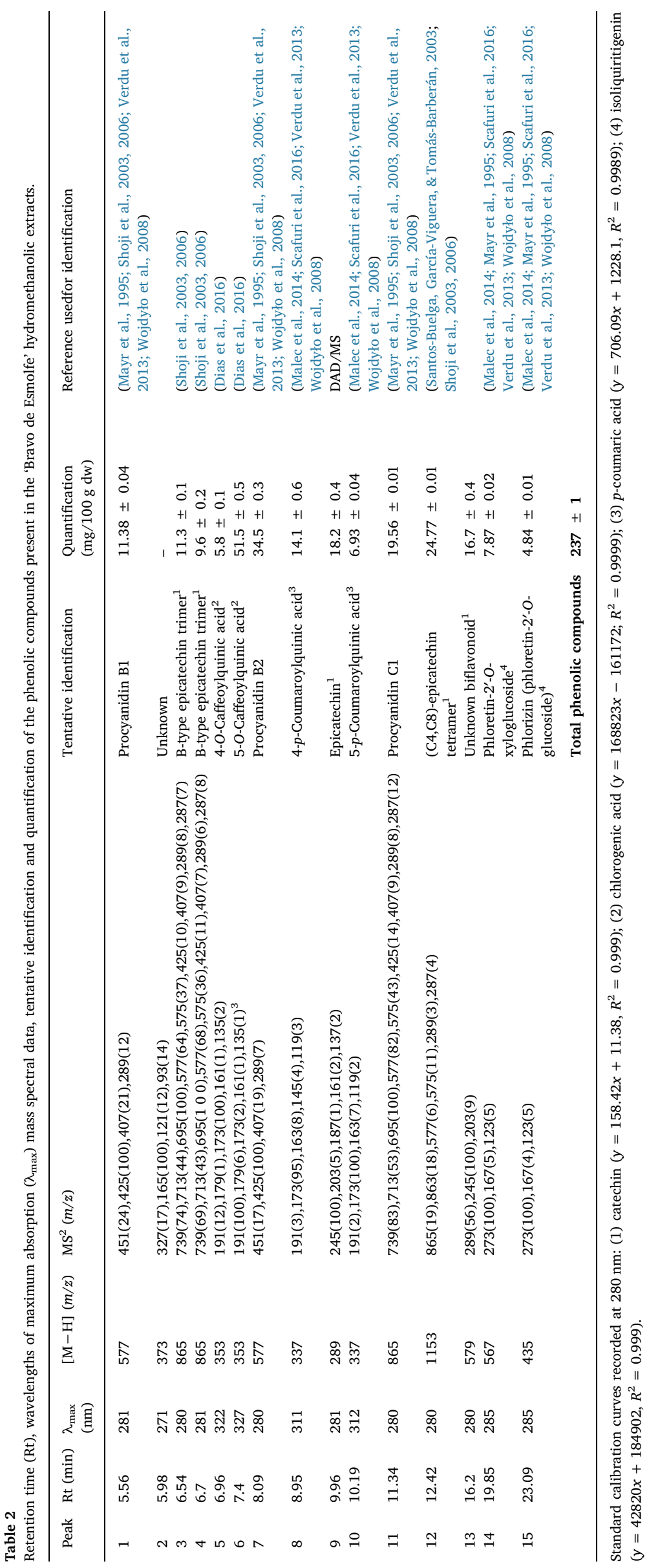


Table 3

Bioactive properties of the 'Bravo de Esmolfe' hydromethanolic extracts (mean $\pm \mathrm{SD})$

\begin{tabular}{ll}
\hline Antioxidant activity $E C_{50}$ values $(\mathrm{mg} / \mathrm{ml})^{*}$ & \\
DPPH scavenging activity & $0.71 \pm 0.05$ \\
Reducing power & $1.38 \pm 0.01$ \\
B-carotene bleaching inhibition & $7.19 \pm 0.04$ \\
TBARS inhibition & $0.45 \pm 0.005$ \\
Antibacterial activity MIC values $(\mathrm{mg} / \mathrm{ml})$ & \\
Gram negative bacteria & \\
Acinetobacter baumannii & $>20$ \\
Escherichia coli & 5 \\
Escherichia coli ESBL & 5 \\
Klebsiella pneumoniae & $>20$ \\
Klebsiella pneumoniae ESBL & $>20$ \\
Morganella morganii & 5 \\
Pseudomonas aeruginosa & $>20$ \\
Gram positive bacteria & \\
Enterococcus faecalis & 5 \\
Listeria monocytogenes & 5 \\
MRSA & 5 \\
MSSA & 2.5 \\
\hline
\end{tabular}

$\mathrm{EC}_{50}$ values correspond to the extract concentration achieving $50 \%$ of antioxidant activity or 0.5 of absorbance in reducing power assay. "Trolox $\mathrm{EC}_{50}$ values: $43.03 \pm 1.71 \mu \mathrm{g} / \mathrm{ml}$ (DDPH), $29.62 \pm 3.15 \mu \mathrm{g} / \mathrm{ml}$ (reducing power), $2.63 \pm 0.14 \mu \mathrm{g} / \mathrm{ml}$ ( $\beta$-carotene bleaching inhibition) and $3.73 \pm 1.9 \mu \mathrm{g} / \mathrm{ml}$ (TBARS inhibition). MIC values correspond to the minimal extract concentration that inhibited the bacterial growth. ESBL - extended spectrum $\beta$-lactamases. MRSA - Methicillin-resistant Staphylococcus aureus. MSSA - Methicillin-susceptible Staphylococcus aureusii.

The phenolic profile of the hydromethanolic extract prepared from 'Bravo de Esmolfe' dried apples, recorded at $280 \mathrm{~nm}$ is shown in Fig. 1. UV and mass spectra could be obtained for fifteen phenolic compounds (Table 2). The main family of compounds were flavan-3-ols, as also reported for other apple varieties (Malec et al., 2014; Scafuri et al., 2016; Verdu et al., 2013; Wojdyło et al., 2008). Epicatechin (peak 9) was positively identified by comparison with a commercial standard. Two B-type (epi)catechin dimers $\left([\mathrm{M}-\mathrm{H}]^{-}\right.$at $m / z 577$, peaks 1 and 7, three trimers $\left([\mathrm{M}-\mathrm{H}]^{-}\right.$at $m / z 865$, peaks 3,4 and 11 and one tetramer $\left([\mathrm{M}-\mathrm{H}]^{-}\right.$at $m / z 1153$, peak 12 were detected. Peaks 1,7 and 11 were identified as procyanidins B1 [epicatechin- $(4,8)$-catechin], B2 [epicatechin-(4,8)-epicatechin], and C1 (5) [epicatechin-(4,8)-epicatechin$(4,8)$-epicatechin] by comparison with our database library; these compounds have been consistently reported as majority procyanidins in apple (Mayr et al., 1995; Shoji et al., 2003, 2006; Verdu et al., 2013; Wojdyło et al., 2008). Peak 12 could be assigned as the $(4,8)$-linked epicatechin tetramer, in coherence with its elution order (SantosBuelga, García-Viguera, \& Tomás-Barberán, 2003) and previous identification in apple (Shoji et al., 2003, 2006). Peaks 3 and 4 might correspond to the trimers epicatechin- $(4,8)$-epicatechin- $(4,8)$-catechin and epicatechin-(4,6)-epicatechin-(4,8)-catechin, also founded in apple (Shoji et al., 2003, 2006). Apple procyanidins are known to be mostly based on epicatechin extension units (Mayr et al., 1995; Shoji et al., 2003, 2006). Peaks 5 and 6 were tentatively identified as 4-O-caffeoylquinic acid and 5-O-caffeoylquinic acid, respectively, based on their fragmentation patterns and elution order (Dias et al., 2016). Similarly, peaks 8 and 10 were tentatively identified as 4-p-coumaroylquinic and 5-p-coumaroylquinic acids. Similar hydroxycinnamoyl derivatives have already been detected in apple (Malec et al., 2014; Scafuri et al., 2016; Verdu et al., 2013; Wojdyło et al., 2008). Peaks 14 and 15 were identified as phloretin-2'-O-xyloglucoside and phlorizin (phloretin-2'-O-glucoside), respectively, chalcones that are also commonly present in apple (Malec et al., 2014; Mayr et al., 1995; Scafuri et al., 2016; Verdu et al., 2013; Wojdyło et al., 2008). Peak 13, presenting a pseudomolecular ion $[\mathrm{M}-\mathrm{H}]^{-}$at $m / z 579$, might correspond to a biflavonoid containing an (epi)catechin unit, owing to the characteristic MS ${ }^{2}$ fragments at $m / z 289,245$ and 203; no identity could be concluded for peak 2. The most abundant compound present in 'Bravo de Esmolfe' variety was 5-O-caffeoylquinic acid (peak 6, $51.5 \mathrm{mg} / 100 \mathrm{~g}$ $\mathrm{dw}$ ), followed by procyanidin B2 (peak 7, $34.5 \mathrm{mg} / 100 \mathrm{~g} \mathrm{dw}$ ).

Data regarding the antioxidant and antibacterial activities of the hydromethanolic extract prepared from 'Bravo de Esmolfe' dehydrated apples are presented in Table 3 . The lowest $\mathrm{EC}_{50}$ values (highest antioxidant activity) were observed in the TBARS inhibition and DPPH scavenging activity assays ( 0.45 and $0.71 \mathrm{mg} / \mathrm{ml}$, respectively). However, Hamauzu, Yasui, Inno, Kume, and Omanyuda (2005) have reported lower $\mathrm{EC}_{50}$ values when using the DPPH scavenging activity methodology in Malus domestica Mill. var. Fuji fruits $\left(\mathrm{EC}_{50}=8.4 \mathrm{mg}\right.$ / $100 \mathrm{ml}$ ), as also Luo, Zhang, Li, \& Shah (Luo, Zhang, Li, \& Shah, 2016) $\left(\mathrm{EC}_{50}=0.26 \mathrm{mg} / \mathrm{ml}\right.$ in a different variety- Fuji). These differences might be related with the studied varieties and the way of preparation of the extracts (e.g., solvents). Regarding the antibacterial results, the hydromethanolic extracts showed the lowest MIC values against Grampositive bacteria, namely methicillin-susceptible Staphylococcus aureus (MSSA) (MIC $=2.5 \mathrm{mg} / \mathrm{ml}$ ). The methicillin-resistant staphylococcus aureus (MRSA) and other Gram-positive bacteria such as Listeria monocytogenes and Enterococcus faecalis had higher MIC values (MIC $=5$ $\mathrm{mg} / \mathrm{ml}$ ). Of the Gram-negative bacteria, Escherichia coli, Escherichia coli (ESBL) and Morganella morganii presented the lowest MIC values (MIC $=5 \mathrm{mg} / \mathrm{ml}$ ). Luo et al. (Luo et al., 2016), also reported antibacterial activity of polyphenolic apple extracts (but from a different variety: Fuji), with lower MIC values. This would be expected, since the cited work used ATCC reference standard microorganisms, while the bacteria used in the present study were obtained from clinical isolates with multiresistant profiles (Dias et al., 2016). Furthermore, the extract studied herein uses different solvents, which can lead to different results.

\section{Conclusion}

Dried apple proved to be a good source of fructose, malic acid, palmitic acid and $\alpha$-tocopherol. Epicatechin and B-type procyanidins, as also hydroxycinnamoyl-quinic acids and phloretin derivatives were the phenolic compounds found in its composition. Furthermore, its hydromethanolic extracts showed antioxidant and antibacterial activity against Gram-positive and Gram-negative bacteria. Overall, this study shows that 'Bravo de Esmolfe' dried apples could be used in snack products with equilibrated nutritional value, and could also be useful in the preparation of nutraceutical formulations with potential antioxidant and antimicrobial properties.

\section{Acknowledgements}

The authors are grateful to Fundação para a Ciência e a Tecnologia (FCT, Portugal) for financial support to CIMO (strategic project UID/ AGR/00690/2013), to REQUIMTE (national funds and co-financed by FEDER, under the Partnership Agreement PT2020) and L. Barros contract. The GIP-USAL is financially supported by the Spanish Government through the project AGL2015-64522-C2-2-R. The authors are also grateful to the Interreg España-Portugal for financial support through the project 0377_Iberphenol_6_E.

\section{References}

AOAC (2016). In W. George, \& J. Latimer (Eds.), Official Methods of Analysis of AOAC International - 20th Edition(20th ed.). AOAC International Retrieved from http:// www.techstreet.com/standards/official-methods-of-analysis-of-aoac-international20th-edition-2016?product_id = 1937367.

Barros, L., Pereira, C. \& Ferreira, I. C. F. R. (2013). Optimized analysis of organic acids in edible mushrooms from portugal by ultra fast liquid chromatography and photodiode array detection. Food Analytical Methods, 6(1), 309-316. http://dx.doi.org/10.1007/ s12161-012-9443-1.

Barros, L., Pereira, E., Calhelha, R. C., Dueñas, M., Carvalho, A. M., Santos-Buelga, C., \& Ferreira, I. C. F. R. (2013). Bioactivity and chemical characterization in hydrophilic and lipophilic compounds of Chenopodium ambrosioides L. Journal of Functional Foods, 
5(4), 1732-1740. http://dx.doi.org/10.1016/j.jff.2013.07.019.

Bessada, S. M. F., Barreira, J. C. M., Barros, L., Ferreira, I. C. F. R., \& Oliveira, M. B. P. P. (2016). Phenolic profile and antioxidant activity of Coleostephus myconis (L.) Rchb. f.: An underexploited and highly disseminated species. Industrial Crops \& Products, 89, 45-51. http://dx.doi.org/10.1016/j.indcrop.2016.04.065.

Bhatti, S., \& Jha, G. (2010). Current trends and future prospects of biotechnological in terventions through tissue culture in apple. Plant Cell Reports, 29(11), 1215-1225. http://dx.doi.org/10.1007/s00299-010-0907-8.

Chinnici, F., Spinabelli, U., Riponi, C., \& Amati, A. (2005). Optimization of the determination of organic acids and sugars in fruit juices by ion-exclusion liquid chromatography. Journal of Food Composition and Analysis, 18(2), 121-130. http://dx.doi. org/10.1016/j.jfca.2004.01.005.

Dias, M. I., Barros, L., Morales, P., Cámara, M., Alves, M.-J., Oliveira, M. B. P. P., ... Ferreira, I. C. F. R. (2016). Wild Fragaria vesca L. fruits: a rich source of bioactive phytochemicals. Food \& Function, 4523-4532.

Dias, M. I., Barros, L., Morales, P., Sánchez-Mata, M. C., Oliveira, M. B. P. P., \& Ferreira, I. C. F. R. (2015). Nutritional parameters of infusions and decoctions obtained from Fragaria vesca L. roots and vegetative parts. LWT - Food Science and Technology, 62(1), 32-38. http://dx.doi.org/10.1016/j.lwt.2015.01.034.

Feliciano, R. P., Antunes, C., Ramos, A., Serra, A. T., Figueira, M. E., Duarte, C. M. M., ... Bronze, M. R. (2010). Characterization of traditional and exotic apple varieties from Portugal. Part 1 - Nutritional, phytochemical and sensory evaluation. Journal of Functional Foods, 2(1), 35-45. http://dx.doi.org/10.1016/j.jff.2009.12.004.

Hamauzu, Y., Yasui, H., Inno, T., Kume, C., \& Omanyuda, M. (2005). Phenolic profile, antioxidant property, and anti-influenza viral activity of Chinese quince (Pseudocydonia sinensis Schneid.), quince (Cydonia oblonga Mill.), and apple (Malus domestica Mill.) fruits. Journal of Agricultural and Food Chemistry, 53(4), 928-934. http://dx.doi.org/10.1021/jf0494635.

Kuete, V., Ango, P. Y., Fotso, G. W., Kapche, G. D. W. F., Dzoyem, J. P., Wouking, A. G., ... Abegaz, B. M. (2011). Antimicrobial activities of the methanol extract and compounds from Artocarpus communis (Moraceae). BMC Complementary and Alternative Medicine, 11(1), 42. http://dx.doi.org/10.1186/1472-6882-11-42.

Kuete, V., Justin, K., Louis, P. S., Bathelemy, N., Herve, M. P., Pantaleon, A., \& Bonaventure, T. N. (2011). Antimicrobial activities of the methanol extract, fractions and compounds from Ficus polita Vahl. (Moraceae). BMC Complementary and Alternative Medicine, 11, 6.

Luo, J., Zhang, P., Li, S., \& Shah, N. P. (2016). Antioxidant, Antibacterial, and Antiproliferative Activities of Free and Bound Phenolics from Peel and Flesh of Fuji Apple. Journal of Food Science, 81(7), M1735-M1742. http://dx.doi.org/10.1111/ 1750-3841.13353.

Malec, M., Le Quéré, J. M., Sotin, H., Kolodziejczyk, K., Bauduin, R., \& Guyot, S. (2014). Polyphenol profiling of a red-fleshed apple cultivar and evaluation of the color extractability and stability in the juice. Journal of Agricultural and Food Chemistry, 62(29), 6944-6954. http://dx.doi.org/10.1021/jf500336v.

Mayr, U., Treutter, D., Santos-Buelga, C., Bauer, H., \& Feucht, W. (1995). Developmental changes in the phenol concentrations of "Golden delicious" apple fruits and leaves. Phytochemistry, 38(5), 1151-1155. http://dx.doi.org/10.1016/0031-9422(94)
00760-Q.

No1107, 96, C. R. (EC) (2001). COMMISSION REGULATION (EC) No 1107/96 of 12 June 1996 on the registration of geographical indications and designations of origin under the procedure laid down in Article 17 of Council Regulation (EEC) No 2081/92. Official Journal of the European Communities, 1992(2), 5-35.

Reis, S. A. R., Rocha, S. M., Barros, A. S., Delgadillo, I., \& Coimbra, M. A. (2009). Establishment of the volatile profile of "Bravo de Esmolfe" apple variety and identification of varietal markers. Food Chemistry, 113(2), 513-521. http://dx.doi.org/10. 1016/j.foodchem.2008.07.093.

Róth, E., Berna, A., Beullens, K., Yarramraju, S., Lammertyn, J., Schenk, A., \& Nicolaï, B. (2007). Postharvest quality of integrated and organically produced apple fruit. Postharvest Biology and Technology, 45(1), 11-19. http://dx.doi.org/10.1016/j. postharvbio.2007.01.006.

Santos-Buelga, C., García-Viguera, C., \& Tomás-Barberán, F. A. (2003). On-line identification of flavonoids by HPLC coupled to diode array detection. In E. C. Santos-Buelga, \& G. Williamson (Eds.), Methods in Polyphenol Analysis. Cambridge: Royal Society of Chemistry.

Scafuri, B., Marabotti, A., Carbone, V., Minasi, P., Dotolo, S., \& Facchiano, A. (2016). A theoretical study on predicted protein targets of apple polyphenols and possible mechanisms of chemoprevention in colorectal cancer. Scientific Reports, 6(August), 32516. http://dx.doi.org/10.1038/srep32516.

Serra, A. T., Matias, A. A., Frade, R. F. M., Duarte, R. O., Feliciano, R. P., Bronze, M. R., ... Duarte, C. M. M. (2010). Characterization of traditional and exotic apple varieties from Portugal. Part 2 - Antioxidant and antiproliferative activities. Journal of Functional Foods, 2(1), 46-53. http://dx.doi.org/10.1016/j.jff.2009.12.005.

Shoji, T., Masumoto, S., Moriichi, N., Kanda, T., \& Ohtake, Y. (2006). Apple (Malus pumila) procyanidins fractionated according to the degree of polymerization using normal-phase chromatography and characterized by HPLC-ESI/MS and MALDI-TOF/ MS. Journal of Chromatography A, 1102(1-2), 206-213. http://dx.doi.org/10.1016/j. chroma.2005.10.065.

Shoji, T., Mutsuga, M., Nakamura, T., Kanda, T., Akiyama, H., \& Goda, Y. (2003). Isolation and structural elucidation of some procyanidins from apple by low-temperature nuclear magnetic resonance. Journal of Agricultural and Food Chemistry, 51(2), 3806-3813. http://dx.doi.org/10.1021/jf0300184.

USDA (2016). USDA National Nutrient Database for Standard Reference Release 28 Retrieved from http://www.ars.usda.gov/Services/docs.htm?docid = 8964 .

Verdu, C. F., Gatto, J., Freuze, I., Richomme, P., Laurens, F., \& Guilet, D. (2013). Comparison of two methods, UHPLC-UV and UHPLC-MS/MS, for the quantification of polyphenols in cider apple juices. Molecules, 18(9), 10213-10227. http://dx.doi. org/10.3390/molecules180910213.

Wojdyło, A., Oszmiański, J., \& Laskowski, P. (2008). Polyphenolic compounds and antioxidant activity of new and old apple varieties. Journal of Agricultural and Food Chemistry, 56(15), 6520-6530. http://dx.doi.org/10.1021/jf800510j.

Wu, J., Gao, H., Zhao, L., Liao, X., Chen, F., Wang, Z., \& Hu, X. (2007). Chemical compositional characterization of some apple cultivars. Food Chemistry, 103(1), 88-93. http://dx.doi.org/10.1016/j.foodchem.2006.07.030. 